\title{
Nova espécie do gênero Ptesimopsia Costa (Coleoptera, Elateridae, Agrypninae)
}

\author{
Simone Policena Rosa ${ }^{1}$
}

${ }^{1}$ Museu de Zoologia, Universidade de São Paulo. Caixa Postal 42494, 04218-970 São Paulo-SP, Brasil. Endereço eletrônico:simonepr@usp.br

\begin{abstract}
New species of the genus Ptesimopsia Costa (Coleoptera, Elateridae, Agrypninae). Ptesimopsia gracilis sp. nov. collected by malaise trap at Fazenda Jaburu, Canindé do São Francisco, Sergipe, Brazil, is described and illustrated.

Keywords. Coleoptera; Elateridae; Ptesimopsia; Pyrophorini; taxonomy.

Resumo. Ptesimopsia gracilis sp. nov. coletada em armadilha malaise na Fazenda Jaburu, Canindé do São Francisco, Sergipe, Brasil, é descrita e ilustrada.

Palavras-chave. Coleoptera; Elateridae; Ptesimopsia; Pyrophorini; taxonomia.
\end{abstract}

O gênero Ptesimopsia foi erigido por CosTA (1975a) para agrupar quatro espécies de vagalumes elaterídeos anteriormente incluídas no gênero Pyrophorus Billberg, 1820. Costa (1975b) revisou o gênero, descreveu três espécies e transferiu Hapsodrilus luculentus (Germar, 1841) para Ptesimopsia, totalizando 8 espécies, todas com distribuição na América do Sul. As espécies deste gênero caracterizam-se principalmente pelas antenas serreadas a partir do terceiro segmento. A nova espécie descrita neste trabalho foi nos enviada para identificação por Luciana Iannuzzi (Programa Xingó, Projeto Biodiversidade da Universidade Federal de Pernambuco, Recife, UFPE). O material tipo está depositado no Museu de Zoologia, Universidade de São Paulo, São Paulo (MZSP).

\section{Ptesimopsia gracilis sp. nov.}

(Figs. 1-4)

Macho (Fig. 1). Tegumento de coloração castanho-escura; antenas, pernas e ângulos posteriores do pronoto castanhoclaros. Pilosidade longa, pouco densa, amarelada e eriçada.

Fronte quadrangular, levemente declinada, proeminente, margem anterior com carena incompleta, superfície côncava; pontuação densa, média e umbilicada. Antenas (Fig. 2) com 11 segmentos, fracamente serreadas a partir do terceiro antenômero, ultrapassando o ângulo posterior a partir do $11^{\circ}$ segmento; $3^{\circ}$ antenômero 2 vezes mais longo que o $2^{\circ}$, os dois juntos 1,2 vezes mais longos que o quarto.

Protórax com lados subparalelos, carenas laterais completas. Pronoto regularmente convexo, com sulco na linha longitudinal mediana; pontuação heterogênea, fina, umbilicada e espaçada na região discal; forte e densa nas margens laterais e anterior. Vesículas luminescentes látero-posteriores, grandes, circulares e salientes. Tubérculo basal ausente. Ângulos posteriores alongados, pouco divergentes, fracamente carenados. Prosterno com pontuação média, espaçada e umbilicada na região mediana, fina e densa nas margens laterais e anterior. Hipômero com pontuação fina, moderadamente densa e umbilicada.

Mesoventrito com região posterior gradualmente inclinada $19^{\circ}$ acima do nível da região anterior. Cavidade mesosternal profunda, de lados subparalelos, 2,3 vezes mais longa que larga, margem posterior arredondada. Metaventrito com pontuação fina, umbilicada, moderadamente densa na região mediana, espaçada nas margens laterais. Metacoxas oblíquas, contíguas, estendendo-se lateralmente até as epipleuras. Placas metacoxais bem desenvolvidas, estreitando-se gradualmente em direção às margens laterais. Sutura longitudinal mediana 0,8 vezes o comprimento do metasterno. Metepisterno alongado, aproximadamente 5,9 vezes mais longo que largo.

Abdômen. Ventritos I a IV com pontuação homogênea, fina e espaçada; ventrito $V$ com pontuação gradualmente maior e mais densa em direção à margem posterior. Órgão luminescente abdominal pequeno (1/5 da largura e $1 / 2$ do comprimento do primeiro esternito) e retangular ( 2,3 vezes mais largo que longo)

Élitros com tegumento fracamente marcado por strigae; interestrias convexas com pontuação fina, espaçada; região anterior com lados subparalelos, gradualmente afilados a partir do terço posterior até os ápices arredondados, largamente marginados.

Pernas delgadas e pilosas. Tíbias comprimidas lateralmente, com dois esporões apicais látero-ventrais; margens interna, externa e bordas do ápice com uma série de cerdas espiniformes. Tarsômeros simples, vertical ou obliquamente truncados na extremidade distal, face ventral densamente pilosa, tarsômeros 1 e 2 com cerdas espiniformes apicais nas margens externa e interna. Garras tarsais simples, com duas cerdas na superfície da base ventral externa e várias cerdas na superfície dorsal.

Edeago (Figs. 3, 4). Peça basal com margem anterior mais esclerotizada. Parâmeros mais curtos que o lobo médio, com 

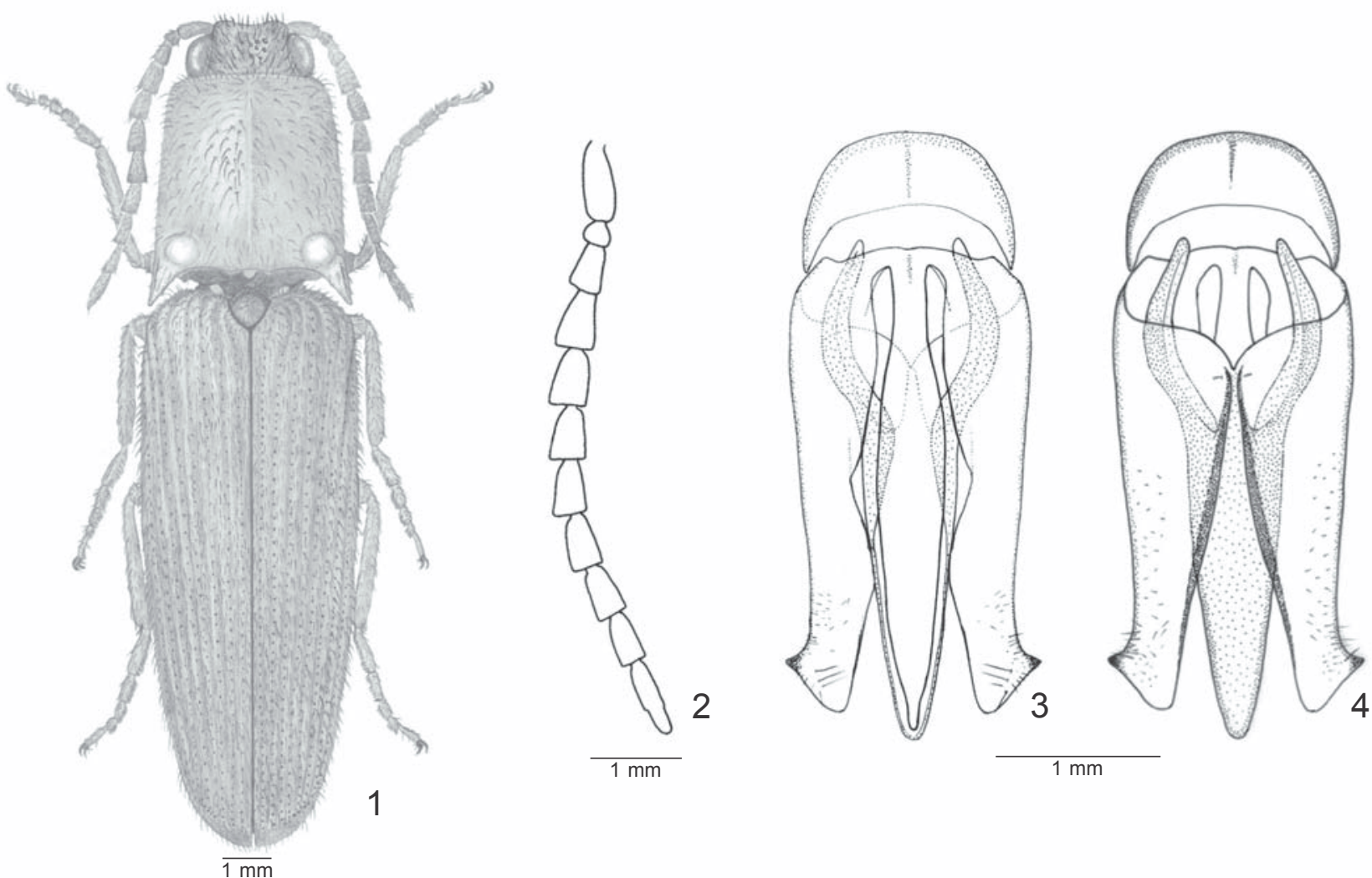

Figs. 1-4. Ptesimopsia gracilis sp. nov. (holótipo): 1, aspecto geral (18,0 mm); 2, antena; 3-4, edeago (ventral, dorsal).

margem dorsal interna dobrada para dentro ápices achatados dorso-ventralmente, com espinho lateral subapical. Lobo médio dorsal articulado com os parâmeros na extremidade basal; lados gradualmente afilados; ápice arredondado; Lobo médio ventral fundido aos parâmeros na base; lados alargados na região mediana, ápice abruptamente afilado.

Dimensões (em mm). Comprimento total: 18,0; comprimento do pronoto: 4,5; largura do pronoto: 4,0; largura umeral: 4,5; comprimento do élitro: 12,4 .

HoLótipo, macho (dissecado). BRASIL. Sergipe: Canindé do São Francisco (Fazenda Jaburu), 17.VIII.2000, L. Ianuzzi col. (malaise), (MZSP). Parátipo, macho: mesmos dados do holótipo, 07.IX.2000, L. Ianuzzi col. (malaise), (MZSP).

Discussão. Ptesimopsia gracilis sp. nov. é caracterizada principalmente pelas antenas fracamente serreadas; nas demais espécies do gênero são fortemente serreadas. É semelhante à P. candezei (Fauvel, 1861) pela pontuação do pronoto fina e pela forma do edeago, mas difere desta pelo corpo mais delgado e élitros gradualmente afilados. É similar à P. luculenta (Germar, 1841) no aspecto geral do corpo, mas difere pela forma do edeago e pontuação do pronoto.

Etimologia. Latim, gracilis $=$ delgado, referente à forma da antena.

Agradecimentos. Ao Dr. Sergio Ide (Instituto Biológico, São Paulo) pela revisão do texto, à Dra. Cleide Costa (MZSP) pela orientação e sugestões, ao Instituto de Biociências da USP e ao Conselho Nacional de Desenvolvimento Científico e Tecnológico - CNPq pelo apoio e financiamento.

\section{REFERÊNCIAS}

Costa, C. 1975a. Sistematics and evolution of the tribes Pyrophorini and Heligmini, with description of Campyloxeninae, new subfamily (Coleoptera, Elateridae). Arquivos de Zoologia 26(2): 49-190.

Costa, C. 1975b. Novas espécies do gênero Ptesimopsia Costa, 1975 (Coleoptera, Elateridae, Pyrophorinae). Papéis Avulsos de Zoologia 29(9): 55-64. 